\title{
Communication in the Engineering Curriculum: Learning to Write and Writing to Learn
}

\author{
Kevin D. Dahm ${ }^{1}$, Stephanie Farrell ${ }^{2}$ and Ravi P. Ramachandran ${ }^{3}$ \\ ${ }^{1,2,3}$ Rowan University College of Engineering, 201 Mullica Hill Road, Glassboro, NJ, 08028, USA \\ 1dahm@rowan.edu
}

\begin{abstract}
Good communication skills are vital for practicing engineers, and there is much literature on strategies for developing communication skills in engineering students. For some years there has been a growing trend in engineering education towards treating communication as an inter-disciplinary skill, and seeking meaningful and pedagogically sound ways to integrate communication skills throughout the engineering curriculum. This paper presents a summary of literature related to writing in the engineering curriculum. It is intended to provide practical resources for engineering faculty, presenting both general guiding principles for writing in the curriculum and specific models that have been used successfully in engineering courses and are readily adaptable in a variety of engineering courses and curricula. The two primary considerations examined are (1) strategies for introducing disciplinary writing into engineering courses and (2) strategies for engaging students in reflective writing.
\end{abstract}

Keywords:Writing,ReflectiveWriting,Communicati on, Communication Across Curriculum, Journal

\section{Kevin D. Dahm}

Rowan University College of Engineering,

201 Mullica Hill Road, Glassboro, NJ, 08028, USA

dahm@rowan.edu

\section{Motivation}

In a survey of 208 engineering graduates conducted in 1999 (Sageev and Romanowski, 2001), respondents indicated that they spent, on average, $64 \%$ of job time on communication: $32 \%$ writing, $10 \%$ oral presentations, and $22 \%$ other oral discussions. This survey also revealed a positive correlation between the likelihood of a respondent being in a management role 3-5 years after graduation and the amount of formal technical communication instruction the respondent experienced as an undergraduate. Respondents who considered themselves good communicators indicated that "their skills differentiate them from the 'pack"' while those who are not comfortable with public speaking (including speaking during meetings) believe "they are considered less competent technically."(Sageev and Romanowski, 2001) Ford and Riley presented a summary of other studies that "suggest that oral and written communication skills are one of the primary factors required of new graduates ultimately affecting their success in the workplace." (Ford and Riley, 2003)

The importance of communication skills have long been reflected in ABET accreditation criteria, but a major shift occurred in 2000. Prior to that, accreditation criteria treated communication as part of the humanities and social sciences (HSS). While the accreditation criteria recognized the value of HSS, requiring that HSS would constitute $13-20 \%$ of the credits in the curriculum, HSS was treated as a 
separate stem of the curriculum, distinct from the technical stem. (Leydens and Schneider, 2009) This encouraged curricular structures in which English or Composition courses were used as primary vehicles for teaching students to write.

In 2000, Boyd and Hassett summarized evidence that at that time, a "competency gap" existed between graduate abilities and workplace expectations, and proposed writing within the discipline as a strategy for closing the competency gap. (Boyd and Hassett, 2000) Also in 2000, ABET shifted the accreditation criteria to an outcomes-based model. The criteria list "an ability tocommunicate effectively" as one of 11 student outcomes required for all engineering programs (ABET, 2015), but the criteria are concerned with evidence that this outcome has been achieved, and do not prescribe how it is to be achieved. Leydens and Schneider (2009), in reviewing how writing was being and had been addressed in engineering programs on six campuses, noted that the shift to outcomes-based accreditation had been a facilitator for change and innovation on several of these campuses. Communication became viewed as an interdisciplinary subject, and five of the six campuses, at the time of publication, had implemented, or were in the process of implementing, Communication across the Curriculum $(\mathrm{CxC})$ in some form.

Yalvac, however, notes some of the challenges that the concepts of CxCand disciplinary writing present for engineering faculty:

"In spite of the movement to incorporate student writing contextually in courses within one's discipline and the research supporting this endeavor (succinctly summarized by Bazerman et al.) (Bazerman et al., 2005, as cited in Yalvac, 2007), faculty are often on their own when it comes to designing integrated writing instruction. Even those faculty members who appreciate the merit of offering writing in content areas may be reluctant to add writing exercises because of the additional work such exercises entail. Many faculty members are also concerned about what they might have to remove from a course to make room for a writing exercise."(Yalvac, 2007, emphasis added)

However, implementing new writing assignments into an engineering course needn't be at the expense of the existing instructional goals of the course. The literature contains numerous examples in which writing has been implemented into engineering courses in ways that not only help student develop better writing skills, but also facilitate better learning of the course material. This paper presents an overview of several published methods for integrating writing into the engineering curriculum, with a focus on models that are readily adopted by other engineering faculty. These models are presented in two sections:

(1) Disciplinary Writing- This section presents strategies for making writing instruction practical and recognizably representative of the kinds of writing engineers do in practice.

(2) Reflective Writing- This section presents writing activities that are designed to promote reflection on course concepts, with the intent of developing deeper understanding, dispelling misconceptions, and/or promotion metacognition in students.

\section{Disciplinary Writing in the Engineering Curriculum}

Engineering students do not generally perceive English or Composition courses as relevant to engineering courses or engineering practice. As stated by Bergman and Zepernick:

" ...we repeatedly observed a tendency among students to actively reject the idea that what they learned about writing in high school or in first year composition (FYC) courses could be applied to the writing they were asked to do in courses in other disciplines.... Their failure to credit English classes with having taught them to write was not, therefore, grounded in students' belief that what they learned about writing in one setting could not be applied in others, but rather in their perception that the writing done for English classes was inherently not "disciplinary" or "professional" and therefore offered few features that could be transferred.

In part, this view seems to arise from students' quite correct understanding of the rhetorical situation of "school writing," which is, as students learn in college, substantially different from any other rhetorical situation they are ever likely to encounter. But it also seems to arise from students' inability to recognize the possibility that English classes, like math and physics classes, might be capable of teaching problem-solving skills whose real-world applications are many and varied. Because they 
believe that the writing done in English classes is personal, expressive, and creative, our students neither recognized the transferable rhetorical problem-solving skills FYC offers nor thought they benefited from the coaching in style, organization, and argument strategies offered in their FYC courses.

A solution to both problems could be provided by a FYC course that introduced students explicitly to the concept of disciplinarity...."(Bergman and Zepernick, 2007)

An example of the strategy described here is given by Lengsfeld, et al. These authors reported on a program that had two existing first-year writing courses and two existing engineering courses. "Critical Reading and Writing develops the students' skills in determining audience, constructing sentences of substance, and developing an organized and unified essay. Engineering Concepts I is a lecture-lab course that emphasizes mechanical drafting skills and handson reverse engineering in order to stimulate design." (Lengsfeld, et al., 2004) The paper describes new linkages between courses, and specific assignments that were introduced in order to demonstrate overlapping in the objectives of the communication course and the design course. This led not only to an improvement in the perceived value of the writing instruction, but also a significant increase in first-year to second-year student retention. It was also done without sacrificing any engineering content or rigor; the authors stated that "engineering faculty, teaching in the sequence, have been able to maintain or increase the technical difficulty of the course content." (Lengsfeld, et al., 2004)

Leydens and Schneider listed four general models for implementing disciplinary writing in engineering:

1. "Disciplinary writing and communication instruction is integrated into technical courses, whose technical instructors have participated in $\mathrm{CxC}$ seminars and have ongoing access to $\mathrm{CxC}$ resources." (Leydens and Schneider, 2009)

2. "Collaborative teaching involving composition and technical faculty in technical courses, wherein the composition faculty member has input into course communication goals and opportunities for direct communication instruction." (Leydens and Schneider, 2009) Another published example of this model is given by Riddell, et al. (2010), who describes a course in which engineering design is taught concurrently with technical communication, by a team consisting of both College of Communication and College of Engineering faculty. These authors discuss synergies between the activities of design and writing.

3. "Linked courses, wherein composition and technical faculty purposefully align their courses so as to maximize benefit for students in both courses. For instance, students in Senior Design may be simultaneously enrolled in a technical communication course in which they learn the rhetorical and communicative nuances of writing design reports and related genres." (Leydens and Schneider, 2009) The aforementioned first year model published by Lengsfeld, et al. also falls into this category.

4. "Stand alone, upper-division technical communication courses taught by composition or technical communication faculty, with input from technical faculty on learning goals and objectives." (Leydens and Schneider, 2009)

Regardless of which curricular structure is used, the literature offers several guiding principles for instructors on how to develop and present writing assignments in engineering courses. The goal is not simply to involve students in the activity of writing; the goal is to develop transferrable writing skills that are applicable to the variety of tasks and settings that they will encounter as practicing engineers. Paretti noted that:

"....current research clearly demonstrates that the development of communication skills relies heavily on situatedlearning, in which the context surrounding an assignment can be as important as the assignment itself. In particular, they (students) may replicate specific document formats, but may not understand the function of those documents in professional contexts and consequently may miss the strategies needed to adapt them to new situations." (Paretti, 2008)

Paretti stresses that situated learning can be promoted by making both the expectations for an assignment and the specific rationale for those expectations clear to the student. Specifically, Paretti offered the following three guidelines for crafting assignments that will help students develop writing skills that are transferrable to the workplace:

૫ "'Creating assignments that meet real faculty 
( and student needs.

( Make those needs explicit within the assignments and the evaluation rubrics.

( Engage students in the process of designing appropriate texts rather than simply fulfilling prescribed formats" (Paretti, 2008)

Beyond the crafting of assignments, Paretti also points out the role that classroom interactions play in situated learning. Paretti conducted a case study on the interactions between faculty and students in a twosemester capstone design experience, including observing regular meetings between the course coordinator (CC) and student teams:

"while the interplay of project management issues and required content in reports and notebooks highlights the potential for situated cognition, often the conversations between the $\mathrm{CC}$ and the team failed to leverage that potential by explicitly connecting the requirements to the ways the $\mathrm{CC}$ hoped to use that information or the ways such information could help the team advance the project. Occasionally, the CC would couple discussions of a more detailed timeline with his desire to see the teams complete their design prior to spring break-a clear link between text and use. More often, however, the discussion involved only simple statements asking for a more detailed timeline or work plan, without explaining the functions that work plan might serve for all participants in the activity system." (Paretti, 2008)

Finally, Yalvac, et al. (2007) recommend that writing modules reflect four key attributes which were adapted from Bransford, et al. (1999):

( Knowledge-centeredness: to help students (a) learn with understanding by organizing knowledge around key concepts and(b) move from novice to expert problem-solving methods.

L Learner-centeredness: to (a) take into account the knowledge, skills, preconceptions, and learning styles of all students and (b) start with what students know when they enter the class.

u Community-centeredness: to (a) encourage students and faculty to learn from one another and (b) situate learning within real-world (authentic) challenges.
? Assessment-centeredness: to (a) provide frequent opportunities for students to make their thinking visible and receive appropriate feedback and (b) revise teaching and learning activities after measuring student learning." (Yalvac, et al., 2007)

The authors discuss a course in the biomedical engineering curriculum, and detail how both writing assignments and in-class writing instruction were refined to address explicitly each of these four key attributes. When this was done, student writing improved measurably compared to the previous year, particularly in the areas of "synthesis" and "argumentation." (Yalvac, etal., 2007)

The next section presents a number of specific "reflective writing" activities that have been used and can be adapted into a wide variety of engineering courses.

\section{Reflective Writing Activities for Engineering Courses}

25 years ago, Windsor reported that:

"...engineers tend not only to see their own knowledge as coming directly from physical reality without textual mediation, but also to devalue the texts engineers themselves produce, seeing them as simple write-ups of information found elsewhere. Scholars and teachers of technical writing have, to some degree, tended to share this view. Several of our most significant studies of engineers' writing, for instance, examine the way writing is used to transmit engineering knowledge rather than to generate it." (Windsor, 1990, emphasis added)

However, the engineering education literature now contains many examples demonstrating the role that the action of writing can play in "knowledge generation." Authors have used writing to teach transferrable skills, increase knowledge, promote a deeper approach to learning, increase conceptual understanding, and improve creativity. This section describes several such writing-to-learn activities that have been used to enhance student learning. Note that these activities are primarily intended to help the writer learn, rather than to transmit information to the reader, and thus exhibit the principles of'knowledgecenteredness" and "learner-centeredness" as presented in the previous section.

Hawkins, et al. (1996) echoed Windsor's point, g 
noting that in the teaching of design, the task of writing was typically dissociated from the design process because the writing of the report was viewed as a final step that occurred after the design was completed. However, these authors also reported changes that occurred when what they termed "incidental writing" was introduced into the design process. "Incidental writing" took the form of informal progress reports generated throughout the project, and served the role "...of capturing and refining thoughts that occur during the design process. We use the term 'incidental writing' to describe writing that fulfills this role, because-unlike formal writingthis type of writing is both concomitant with the engineering process and prompted by specific incidents that students encounter as they experiment with their designs." Benefits of introducing incidental writing into a design course were reported by the authors as follows: "incidental writing serves as a tool for

( Improving writing skills,

u Communicating with instructors, and

\section{Improving knowledge and cognitive abilities."}

The authors also presented examples of journal entries produced by students that demonstrated evidence of self-awareness and metacognition. (Hawkins, et al., 1996)

Maharaj and Banta (2000) used four types of writing-to-learn (WTL) assignments in a sophomorelevel mechanics course to promote students' understanding of course content and to increase the students' active role in the learning process. The four types of assignments were chapter summaries, a nalogies, word problems and explanations/explorations. Chapter summaries focused on the main concepts, definitions, sketches, and applications of ideas. The objective of the chapter summaries was to equip students with other methods of learning, studying and organizing material. Analogies required students to think of real world examples that connected course conceptual content with the physical world. The objective was to develop students' ability to visualize and enhance their intuitive feel of course concepts. Explanations/explorations assignments required students to explain concepts that they found difficult. The objective of these activities was to improve students' ability to assess critically their conceptual understanding and to advance concepts from the passive memory into the active memory. The word problem writing assignments required students to explain a solution process for a homework problem using prose, diagrams and equation (without actually solving the problem). The objective of the word problem assignments was to support students' development of logical, systematic approaches to problem solving, rather than haphazard or plug and chug techniques. A comparable exercise was described by Hanson and Williams, who called theirs an "explain-a-problem" writing assignment. (Hanson and Williams, 2008) Maharaj and Banta evaluated the effectiveness of their WTL activities through student interviews three times during the semester. The authors reported that all WTL activities were met initially with student resistance, skepticism and dread, but as the semester progressed students found techniques that suited their learning approach and adapted these in their logs. Students recognized the benefits of the WTL exercises including better organization and retention of material, better connection to their personal experiences, and a transition from passive to active learning. By the end of the semester all of the students interviewed reported experiencing benefits from the WTL assignments and reported the intention to use selected strategies in the future, and students were most positive about the chapter summaries. (Maharaj and Banta, 2000)

Burrows, et al., (2001) describe a course structure in which students completed reading assignments and then wrote 1-2 page journal entries about their significance. The reading assignments were mandatory and there was a quiz on each, while the journaling was voluntary. These authors showed that reflective journal enhances conceptual understanding and additionally improves learning of content. The optional journaling was assigned at the beginning of the semester with the purpose of encouraging students to reflect on concepts during assigned reading. Students were asked to summarize important concepts, make a list of questions about content that was unclear to them, describe possible real-world applications of concepts, relate the new concepts to their own experiences and compare the concepts in this class to the material in other classes. The authors demonstrate that the students who chose to write in journals performed better on class quizzes addressing the knowledge level of learning than those who did not write in journals. The authors also demonstrated that individual students who only journaled some of the 
time performed better on quizzes when they did journal compared with when they did not journal. (Burrows, et al., 2001)

In contrast with the study by Burrows et al. that used journaling to increase knowledge-level learning, Korgel used optional journal writing exercises to improve deep learning and creativity. Korgel describes a journaling activity in which, once a week, students were challenged to produce an analogy related to a specific concept. "The journal prompt can be used to either catalyze review of material covered in previous courses or encourage the active exploration of a new concept. Students are free to respond with illustrations, text, derivations, sample problems, etc." (Korgel, 2002) The instructor then chose 3-5 of the best analogies and presented them anonymously to the class, and extra credit was awarded to the student whose analogy was voted by the class as the "best". A primary benefit of the activity was the class discussion that preceded the vote. "Since the analogies often describe real-life experiences, students feel closely connected to the discussion, which effectively promotes dialogue between the students and the instructor." (Korgel, 2002) In this study, students reported that the journals helped them develop deeper conceptual understanding. The distinction between knowledgelevel learning and deeper conceptual understanding was also considered by Sharp, et al. (1997) and Randolph (2000), who examined how writing activities can be used to engage students at all six levels of understanding described by Bloom's Taxonomy (Bloom, 1967).

Sharp et al. (1999) proposed several types of writing assignments that meet the needs of different learning styles to enhance learning in engineering courses. The four WTL strategies presented in this paper include analyzing job-related Web searches and engineering job preparation, using peer editing to revise assignments, using journals to learn to write and to write to learn, and using a paper airplane activity to teach students how to write instructions. In the Web search and job preparation assignments described in the section by Sharp, students searched several websites for jobs in their majors, identified the skills and credentials sought by employers, and researched the specific companies. They produced a short summary of this information along with a job skills analysis chart, and rated their own credentials against the employer requirements. They also produced a short report on their search processes. The authors proposed learning outcomes from this activity were web searching, skills valued by industry. (Sharp et al. 1999)

Co-author Olds describes a second activity in which peer editing is used to review student work holistically, focusing on organization, style, clarity and logic. The students gain practice in revising their own writing and critiquing the writing of their peers. Students benefit from the feedback as well as from seeing how their peers approached the same topic. The result is an improved product that takes less faculty time to grade. (Sharp et al. 1999)

The third activity described in the section by Miller is a journaling activity used in a fluid mechanics course. The activity is used to help students make meaning of the content by articulating connections between familiar concepts and new ones, and to provide feedback to the instructor on each student's progress. Students were asked to clarify questions on confusing topics, extend the analysis of classroom topics to everyday phenomena, and provide feedback on all aspects of the class. The author reported that the activities were initially met with resistance, but by the end of the semester most of the students realized that journaling helped them learn the course content. (Sharp et al. 1999)

Co-author Dyrud describes a simple activity designed to emphasize important aspects of technical documentation for instructions. Students make a paper airplane, then write instructions to describe the process to peers. The peers then use the written instructions to replicate each other's airplanes. Students learn to appreciate the importance of accuracy, clarity, audience, and graphics in technical writing. (Sharp et al. 1999)

Finally, Felder and Brent(1992) describe a variety of simple writing assignments that enhance students' interest in course material and facilitate a deeper approach to learning. In the beginning of the course, the instructor can ask students what they've heard about the course and what their expectations are. This helps the both the instructor and the students to become aware of the students' attitudes and feelings. Prior knowledge can be activated through writing assignments that ask students to list what they already know about a topic. Generating a list of questions helps students identify what they already know and what they don't yet know; making predictions about what they think will happen provides motivation for 
learning future material. Assignments that ask students to relate new concepts to everyday observations can help promote a deep approach to learning. As a course proceeds, assignments that ask students to summarize material can help promote organization, clarity and logic, and it can help refocus students when content becomes overwhelming. Critical thinking can be developed through writing assignments that require students to analyze information and to make and justify conclusions. Creativity can be taught through writing activities that ask students to think of several approaches to solving a problem or to troubleshoot a situation. To develop deep thought, students could complete an assignment that requires them to design an exam problem that requires application of higher levels of thinking according to Bloom's (1967) taxonomy. (Felder and Brendt, 1992)

\section{Summary}

A review of the engineering education research literature reveals a variety of strategies used by instructors to integrate writing into the engineering curriculum. Two broad categories of writing activities emerge: disciplinary writing exercises in which students "learn to write" and reflective writing exercises in which students "write to learn". Across both categories, student resistance to writing is commonly encountered due to a dualistic perception of writing and engineering as separate from each other. However, student resistance decreases as the perceived value of written communication and the benefits of the writing activities increases with regular and carefully designed assignments. This paper has provided examples of disciplinary writing assignments with structure and content that make writing relevant to students and help them develop transferrable skills. In addition, a variety of reflective exercises are included that develop creativity, promote conceptual understanding and encourage a deeper approach to learning.

\section{References :}

ABET, Inc., "Criteria for Accrediting Engineering Programs, 2015-2016" available at http://www.abet.org/accreditation/accreditationcriteria/criteria-for-accrediting-engineeringprograms-2015-2016/, accessed 8/21/2015.

Bergmann, L. S., \&Zepernick, J. Disciplinarity and transfer: Students' perceptions of learning to write. WPA: Writing Program Administration, 31, 1-2, (2007).
Bloom, B. S., ed. Taxonomy of educational objectives: Handbook I: Cognitive domain. New York, David McKay, 1967.

J. Bransford, A. Brown and R. Cocking, How People Learn: Brain, Mind, Experience, and School, National Academy Press, Washington, D.C., 1999.

G. Boyd and M. Hassett, "Developing Critical Writing Skills in Engineering and Technology Students," Journal of Engineering Education, 89, 4 (2000).

V. Burrows, B. McNeill, N. Hubele and L. Bellamy, "Statistical Evidence for Enhanced Learning of Content through Reflective Journal Writing," Journal of Engineering Education, 90, 4(2001).

M. Eliot and J. Turns, "Constructing Professional Portfolios: Sense-Making and Professional Identity Development for Engineering Undergraduates," Journal of Engineering Education, 100, 4 (2011).

R. Felder and R. Brent, "Writing Assignments Pathways to Connections, Clarity, Creativity," College Teaching, 40, 1, (1992).

J. Ford and L. Riley, "Integrating Communication and Engineering Education: A Look at Curricula, Courses, and Support Systems," Journal of Engineering Education, 92, 4(2003).

N. Gnanapragasam, "Evolution of Technical Writing in Senior Design-A Case History," Advances in Engineering Education, 2, 1 (2010).

J. Hanson and J. Williams, "Using Writing Assignments to Improve Self-Assessment and Communication Skills in an Engineering Statics Course," Journal of Engineering Education, 97, 4 (2008).

S. Hawkins, M. Coney and K. Bystrom, "Incidental Writing in the Engineering Classroom," Journal of Engineering Education 85, 1 (1996).

B. Korgel, "Nurturing Faculty-Student Dialogue, Deep Learning and Creativity through JournalWriting Exercises," Journal of Engineering Education 91, 1(2002).

C. Lengsfeld, G. Edelstein, J. Black, N. Hightower, M. Root, K. Stevens and M. Whitt, "Engineering Concepts and Communication: A Two-Quarter Course Sequence" Journal of Engineering Education 93, 1 (2004).

J. Leydens and J. Schneider, "Innovations in Composition Programs that Educate Engineers: Drivers, Opportunities and Challenges," Journal of Engineering Education, 98, 3 (2009).

S. Maharaj and L. Banta, "Using Log Assignments to Foster Learning: Revisiting Writing across the Curriculum," Journal of Engineering Education, 89, 1 (2000). 
M. Paretti, "Teaching Communication in Capstone Design: The Role of the Instructor in Situated Learning," Journal of Engineering Education, 97, 4 (2008).

G. Randolph, "Collaborative Learning in the Classroom: A Writing Across the Curriculum Approach," Journal of Engineering Education, 89, 2 (2000).

W. Riddell, J. Courtney, E. Constans, K. Dahm, R. Harvey and P. von Lockette, "Making communication matter: integrating instruction, projects and assignments to teach writing and design," Advances in Engineering Education, 2, 2 (2010).

J. Sharp, J. Harb and R. Terry, "Combining Kolb
Learning Styles and Writing to Learn in Engineering Classes," Journal of Engineering Education, 86, 2 (1997).

J. Sharp, B. Olds, R. Miller and M. Dyrud, "Four Effective Writing Strategies for Engineering Classes," Journal of Engineering Education, 88, 1 (1999).

D. Windsor, "Engineering Writing/Writing Engineering," College Composition and Communication, 41, 1 (1990).

B. Yalvac, H. Smith, J. Troy and P, Hirsch, "Promoting Advanced Writing Skills in an Upper-Level Engineering Class," Journal of Engineering Education, 96, 2(2007). 